\title{
規準化直接オブリミン解の標準誤差
}

\author{
小樽商科大学 小笠原春彦
}

\section{Standard errors for the direct oblimin solution with Kaiser's normalization}

Haruhiko Ogasawara (Department of Information and Management Science, Otaru University of Commerce, Midori, Otaru 047-8501)

Kaiser's normalization is widely used in factor rotation. In this paper the asymptotic standard errors for rotated parameters are obtained when Kaiser's normalization is employed for the direct oblimin method which is one of the most frequently used oblique rotations. The method of estimating the standard errors is based on the augmented information matrix for parameters with restrictions. A Monte Carlo simulation is carried out to confirm the accuracy of the method. Further, it is shown by artificial data that the values of the standard errors with Kaiser's normalization can be significantly different from those without the normalization. That is, Kaiser's normalization tends to decrease the standard errors of the loadings for the variables with small communalities and to increase those of the correlations among oblique factors.

Key words: Kaiser's normalization, direct oblimin, standard errors, information matrix, restriction for estimators.

因子分析における回転の方法にはさまざまなものが あるが，各観測変数の回転における影響の大きさを均 一にするためにいわゆる Kaiserによる規準化を行う ことが多い.これは回転の対象となる負荷行列を各観 測変数の共通性の平方根で除し, 新たな共通性をすべ て1にした上で回転し，回転後にもとの共通性になる ように負荷行列を再び変換するものである。すなわ ち, $p$ 変量 $k$ 因子の回転前負荷行列を $\Lambda(p \times k)$, 回 転 (変換) 行列を $T(k \times k), i$ 番目の変数の共通性 の平方根 $\left(\sqrt{c_{i}}\right)$ を $i$ 番目の対角要素とする対角行列を $C(p \times p)=\operatorname{diag}\left(\sqrt{c_{1}}, \cdots, \sqrt{c_{p}}\right)$ とすると, 回転（直交 または斜交）の対象となる負荷行列は $C^{-1} \Lambda$ であり, 回転後の負荷行列 $B$ は

$$
B=C\left(C^{-1} \Lambda T\right)=\Lambda T
$$

である。

典型的な統計解析プログラムパッケージである SAS (SAS Institute Inc., 1990), BMDP (Dixon, 1992), SPSS（SPSS Inc., 1990）では回転を行う場合 は Kaiser による規準化の有無を選択できるが，デフ オルト值はいずれも規準化を行うようになっている。 したがって，現在までに因子分析の適用においておび ただしい数の分析が規準化をともなって行われてきた と推測される。

ところで, 因子分析結果の評価には実質科学的な知 識に基づく因子の解釈とともにさまざまな統計的な指
標が有用である.そのひとつはパラメータの推定值の 標準誤差である。直交回転後の因子負荷の標準誤差の 一般的な導出方法は Archer \& Jennrich（1973）抢よ びJennrich (1974) によって得られた。これらの結果 に基づき，最もよく使用される回転法のひとつである バリマックス法を含むオーソマックス法について, Kaiserの規準化をともなう解の標準誤差は小笠原 （1996）によって示された.

一方, 斜交回転後の結果については一般的な標準詋 差の導出方法はJennrich（1973）によって得られ，一 般化されたCrawford-Ferguson 族（後に“4 次基準の 一般化対称族”（Clarkson \& Jennrich, 1988）と呼ばれ るもの）に対して，具体的な計算方法が示された。 たプロマックス法についてはOgasawara（1998a） により，直交・斜交プロクラステス法については Ogasawara（1999）により，回転解の標準誤差が示さ れた.しかし，これらの回転はKaiserの規準化をと もなわないケースを対象としたものである。

行動科学でよく用いられる相関行列を対象とした斜 交回転解については Ogasawara（1998b）は情報行列 を用いた標準誤差の導出方法を示し, 素（raw; Kaiserの規準化を行わない意) 直接および間接オブリミ ン解について具体例を与えた。 また, 同論文には回転 後の因子寄与の標準誤差の算出方法も示されている. 本研究では斜交回転解のうち最も一般的な方法のひ 
とつである直接オブリミン法 (Jennrich \& Sampson, 1966 参照）の解について Kaiser の規準化をともなう 場合の標準誤差の求め方を示す.

\section{斜交解におけるパラメータの制約}

因子負荷を対象とする斜交回転後のパラメー夕の制 約とそれに基づく標準誤差の一般的な解法は前述のよ うにJennrich（1973）により得られたが，その導出過 程は複雑である。Ogasawara（1998b）は同じ制約を ラグランジュの未定乗数法を用いて簡単に求めている ので，その要点を記す。

回転前の直交因子の負荷行列を $\Lambda(p \times k)$ とすると 回転後の結果は

$$
B=\Lambda T^{\prime-1}, \Phi=T^{\prime} T, \operatorname{Diag}(\Phi)=I_{k}
$$

である。ここで $B, \Phi$ は回転後斜交因子の負荷行列と 相関行列である。 $I_{k}$ は $k$ 次の単位行列であり, $\operatorname{Diag}(\cdot)$ は ( )内の行列の非対角要素を 0 とすること を表す. 回転後の $B$ の推定值は $B$ の何らかの関数で ある $u(B)$ を最適化するものである。回転行列 $T$ に 制約があるのでラグランジュの未定乘数を対角要素と する対角行列 $L(k \times k)$ を導入すると $B$ の推定値は次 の $f$ を極値化するものとして得られる。

$$
f=u(B)+\frac{1}{2} \operatorname{tr}\left\{\left(T^{\prime} T-I_{k}\right) L\right\}
$$

ここで $f$ の $T$ に関する微分をとると

$$
\begin{aligned}
d f & =\operatorname{tr}\left(\frac{\partial u}{\partial B^{\prime}} d B\right)+\operatorname{tr}\left(L T^{\prime} d T\right) \\
& =\operatorname{tr}\left\{\left(-T^{-1} \Lambda^{\prime} \frac{\partial u}{\partial B} T^{-1}+L T^{\prime}\right) d T\right\}
\end{aligned}
$$

となる. $\partial f / \partial T=O$ より，

$$
T^{-1} \Lambda^{\prime} \frac{\partial u}{\partial B} T^{-1}=L T^{\prime}
$$

が得られる。右より $T\left(T^{\prime} T\right)^{-1}$ をかけと

$$
B^{\prime} \frac{\partial u}{\partial B} \Phi^{-1}=L
$$

である。すなわち，左辺の $k^{2}-k$ 個の非対角要素を 0 とおいた式が $B$ と $\Phi$ に関する制約となる。 $B$ と $\Phi$ の漸近標準誤差は最尤解においては制約付推定量の標 準誤差を求める一般的な方法である搪大された情報行 列を用いる方法から得られる (Silvey, 1975 参照).

\section{規準化直接オブリミン解の標準誤差}

素值接オブリミン基準は $\beta_{i j}=(B)_{i j}$ とすると

$$
u_{0}=\frac{1}{4} \sum_{u>v}\left\{\sum_{i=1}^{p} \beta_{i u}^{2} \beta_{i v}^{2}-\frac{\gamma}{p}\left(\sum_{i=1}^{p} \beta_{i u}^{2}\right)\left(\sum_{i=1}^{p} \beta_{i v}^{2}\right)\right\}
$$

である。ここで， $\gamma$ は多くの場合 $0-10$ 值が用いら れる，オブリミン・ウェイトである。規準化（以下

“Kaiserの”を略す）オブリミン法の最適化基準は

$$
\begin{aligned}
u & =\frac{1}{4} \sum_{u>v}\left\{\sum_{i=1}^{p} \frac{\beta_{i u}^{2} \beta_{i v}^{2}}{c_{i}^{2}}-\frac{\gamma}{p}\left(\sum_{i=1}^{p} \frac{\beta_{i u}^{2}}{c_{i}}\right)\left(\sum_{i=1}^{p} \frac{\beta_{i v}^{2}}{c_{i}}\right)\right\} \\
c_{i} & =\left(B \Phi B^{\prime}\right)_{i i}
\end{aligned}
$$

である. 式(6)の左辺 $(r, s)$ 要素を $g_{r s}$ とし， $c_{i}$ は 陆に功わらず一定であることに注意すると

$$
\begin{array}{r}
g_{r s}=\frac{1}{2} \sum_{i=1}^{p} \sum_{j=1}^{k} \sum_{v \neq j}\left(\frac{\beta_{i v}^{2}}{c_{i}}-\frac{\gamma}{p} \sum_{m=1}^{p} \frac{\beta_{m v}^{2}}{c_{m}}\right) \frac{\beta_{i j} \beta_{i r}}{c_{i}} \phi^{s j} \\
(r \neq s)
\end{array}
$$

となる。ここで $\phi^{s j}=\left(\Phi^{-1}\right)_{s j}$ であり,また $\phi_{s j}=$ $(\Phi)_{s j}$ とする。式(9)を $k^{2}-k$ 個の要素をもつべクトル に並べたものを $g$ とすると $\underline{g}=\underline{0}$ が制約式となる.

以上の制約式は共分散行列のモデルと相関行列のモ デルのいずれにもあてはまるものであるが，母共分散 行列の構造モデルは各モデルの順に次のようになる。

$$
\begin{aligned}
& \sum=B \Phi B^{\prime}+\Psi, \\
& \Sigma=D\left(B \Phi B^{\prime}+\operatorname{Diag}\left(I_{p}-B \Phi B^{\prime}\right)\right) D
\end{aligned}
$$

ここで $\Psi$ は独自性を対角要素とする対角行列， $D$ は 観測変数の母標準偏差を対角要素とする対角行列であ る. 式(9)の各モデル別にパラメー夕を並べたべクト ルを $\underline{\theta}$ として般的に表すと, 拡大された情報行列 $I$ の逆行列は

$$
I^{-1}=\left[\begin{array}{cc}
I(\underline{\theta}), & \frac{\partial \underline{g}^{\prime}}{\partial \underline{\theta}} \\
\frac{\partial \underline{g}}{\partial \underline{\theta}^{\prime}}, & O
\end{array}\right]^{-1}=\left[\begin{array}{cc}
I^{*}(\underline{\theta}), & \# \\
\#, & \#
\end{array}\right]
$$

とかける。 $I(\theta)$ は $\theta$ に関する情報行列で共分散行列 モデルではよく知られている。相関行列の場合は Ogasawara（1998b）に示されている. $I^{*}(\theta)$ は $I^{-1}$ に おいて $\underline{\theta}$ に対応する部分行列で，\#はそこに適当な値 が入ることを表す。首の最尤推定量の漸近共分散行列 は $I^{*}(\underline{\theta})$ であり，これに $\underline{\theta}$ の推定值を代入するとそ の推定值が得られる。 $\partial \underline{\mathrm{g}^{\prime}} / \partial \underline{\partial \theta}$ の具体的な形は付録に ある。

\section{因子寄与の標準誤差}

斜交回転後の因子寄与は直交回転の場合と異なりさ まざまに定義される。たとえば Harman（1976）では 各因子ごとの因子負荷の 2 乗和（直接寄与）や異なる 因子間の $2 \times$ 共分散の和（結合寄与）を定義し，柳 井・繁栘・前川・市川（1990）では $B \Phi の ~ i$ 列の 2 乗 和（他の因子を無視した寄与; 以下 $c_{n i}$ ）や $i$ 因子と 規準化された反イメージの共分散の 2 乗和（ $i$ 因子以 外の因子の影響を除いた寄与；以下 $c_{e i}$ ) を挙げてい る。これらの標準誤差は Ogasawara（1998b）が素直 接オブリミン解について求めているが，規準化直接才 ブリミン解の場合も同様の方法が利用できる.

すなわち，ある因子に関する各種の寄与を一般的に $c_{*}$ で表すと, $c_{*}$ は $B$ と $\Phi$ のる関数であるが，デ ル夕法により,

$$
I^{*}\left(c_{*}\right)=\frac{\partial c_{*}}{\partial \underline{\theta^{\prime}}} I^{*}(\underline{\theta}) \frac{\partial c_{*}}{\partial \underline{\theta}}
$$

と表され，これが $c_{*}$ の溸近分散となる， $\partial c_{*} / \partial \underline{\theta}$ はた とえば上記の $c_{n i}$ と $c_{e i}$ の場合 
Table 1

Rotated results by direct oblimin method $(\gamma=0)$

\begin{tabular}{|c|c|c|c|c|c|c|c|c|}
\hline \multicolumn{2}{|c|}{ Variable } & \multicolumn{3}{|c|}{$\begin{array}{l}\text { Raw oblimin } \\
\text { Loadings }\end{array}$} & \multicolumn{3}{|c|}{$\begin{array}{c}\text { Normal oblimin } \\
\text { Loadings }\end{array}$} & \multirow{2}{*}{$\begin{array}{l}\text { Comm- } \\
\text { unality }\end{array}$} \\
\hline & No. & I & II & III & I & II & III & \\
\hline \multirow{3}{*}{ Data A } & 3 & .62 & .16 & & .61 & .17 & & .53 \\
\hline & 6 & -.03 & .83 & & -.06 & .84 & & .65 \\
\hline & $\phi_{21}$ & .61 & & & .62 & & & \\
\hline SS of structures & & 2.13 & 2.20 & & 2.12 & 2.23 & & \\
\hline Anti-image cont. & & .90 & .97 & & .87 & .98 & & \\
\hline \multirow{3}{*}{$\begin{array}{l}\text { Twelve psycho. } \\
\text { tests }\end{array}$} & 4 & -.11 & .72 & .07 & -.10 & .71 & .07 & .48 \\
\hline & 8 & .79 & .04 & .04 & .79 & .05 & .04 & .71 \\
\hline & 12 & -.01 & -.01 & .54 & -.03 & -.02 & .55 & .28 \\
\hline \multicolumn{2}{|c|}{$\phi_{21}, \quad \phi_{31}, \quad \phi_{32}$} & .53 & .58 & .40 & .52 & .61 & .43 & \\
\hline \multicolumn{2}{|l|}{ SS of structures } & 4.05 & 3.66 & 2.79 & 4.04 & 3.64 & 2.93 & \\
\hline \multicolumn{2}{|l|}{ Anti-image cont. } & 1.40 & 1.73 & .70 & 1.38 & 1.72 & .70 & \\
\hline
\end{tabular}

$$
c_{n i}=\sum_{j=1}^{p}\left(\sum_{u=1}^{h} \beta_{j u} \phi_{u i}\right)^{2}, \quad c_{e i}=\sum_{j=1}^{p} \beta_{j i}^{2} / \phi^{i i}
$$

より容易に得られる。 Ogasawara（1998b）にはこれ らを含む 4 種の寄与について $\partial c_{*} / \partial \theta$ が示されている.

\section{数值例による考察}

以上は規準化オブリミン解におけるパラメータの最 尤推定量の漸近分散の理論的な結果である. 数值例の 前半ではその適切性を確かめるためにシミュレーショ ンの結果を示す.ところで，オブリミン法では Jennrich \& Sampson（1966）が指摘しているように $\gamma$ $=0$ のクォーティミン法で単純構造が得られるのに $\gamma$ $=0$ 以外では (バイクォーティミン法, コバリミン法 など）では単純構造にならないことがある，著者も実 際にこれを経験している.さらに, 直接オブリミン法 では $\gamma=0$ 以外では解の収束が得られないことも珍し くない。そこで, 実際場面で有用性の高いと考えられ る $\gamma=0$ の直接クォーティミン法についてのみ検討す る.

シミュレーションのためのデータは二つであり，第 一のもの（以下デー夕A）は次の人工的な直交因子 の負荷行列 $\Lambda$ を回転前の構造として設定している. また，観測変数の母分散はすべて 1 とした。

$$
\Lambda^{\prime}=\left[\begin{array}{llllll}
.7 & .7 & .7 & .4 & .4 & .4 \\
.0 & .1 & .2 & .5 & .6 & .7
\end{array}\right]
$$

第二のデータは Harman（1976, p. 401）の120心理 テストの相関行列 $(N=355)$ である. 各デー夕にそれ ぞれ 2 因子または 3 因子を仮定し, 規準化直接オブリ ミン解を求めたもの（一部）が Table 1 亿示されてい る. 12 の心理テストデータでは回転前の解は最尤解 である。規準化の有無による因子パターンと寄与の相 違は，共通性にかなり異なるものが含まれているにも かかわらず（特に 12 の心理テストデー夕）わずかで
ある。

Table 2, 3 の $N$ の見出しに対応する数值は共分散 および相関行列の各モデルの素および規準化オブリミ ン解 $(\gamma=0)$ に関する代表的なパラメータと寄与の理 論的な標準誤差である. 見出しの $\mathrm{S}$ の数值はシミュ レーションによる結果であるが，これは次のようにし て求めた。すなわち, 二つのデー夕の各因子分析結果 から再構成した相関行列を母共分散行列とみなして, 被験者数（データ A では 300 を仮定）に等しい標本 を多変量正規分布を仮定して無作為に発生させる. 次 にこの標本からひとつのオブリミン解を求める。この 手続きを 1000 回繰り返し, 1000 回の推定值から求 めた標準偏差をシミュレーションによる標準誤差とす る. Table 2，3の規準化オブリミン解の $\mathrm{N}$ と $\mathrm{S}$ の標 準誤差を比べると両者はかなり接近していて, 理論的 な值の正しさが示唆されている.

しかし，あわせて示されている素オブリミン解の結 果をみると，もともと規準化の有無による因子パター ンの相違が小さいことに対応して, 規隼化オブリミン 解の標準誤差との相違がわかりにくい. そこで次のよ うな単純な指標の結果を示す。素および規準化オブリ ミン解の理論的な標準誤差をそれぞれ $N r, N n$ とし, 同じくシミュレーションによるものを $S r, S n$ とす る. 表の H (hit) は $(N r>N n$ かつ $S r>S n)$ または $(N r<N n$ かつ $S r<S n)$ を表し, F (fail) は $(N r>$ $N n$ かつ $S r<S n)$ または $(N r<N n$ かつ $S r>S n)$ を 表し, 一は等号を含む場合とする。この結果, 表では データ A の場合は表にない負荷の部分に共分散およ び相関行列の各モデルにひとつずつ Fがあるほかは すべてHである。12の心理テストのデータでも表に ない部分では共分散および相関行列の各モデルの負荷 にひとつずつ一があるほかはすべて Hで，Fは表の 寄与の部分に二つあるだけである。これらのデー夕は 
Table 2

Standard errers for artificial data A (direct oblimin, $\gamma=0$ )

\begin{tabular}{|c|c|c|c|c|c|c|c|c|c|c|c|}
\hline & \multirow{3}{*}{$\begin{array}{c}\text { Variable } \\
\text { No. }\end{array}$} & \multicolumn{5}{|c|}{ Covariance model } & \multicolumn{5}{|c|}{ Correlation model } \\
\hline & & \multicolumn{2}{|c|}{ Raw } & \multicolumn{2}{|c|}{ Normal } & \multirow[b]{2}{*}{$\mathrm{H} / \mathrm{F}$} & \multicolumn{2}{|c|}{ Raw } & \multicolumn{2}{|c|}{ Normal } & \multirow[b]{2}{*}{$\mathrm{H} / \mathrm{F}$} \\
\hline & & $\mathrm{N}$ & $\mathrm{S}$ & $\mathrm{N}$ & $\mathrm{S}$ & & $\mathrm{N}$ & $\mathrm{S}$ & $\mathrm{N}$ & S & \\
\hline Factor I & 3 & .0905 & .0895 & .0863 & .0864 & $\mathrm{H}$ & .0821 & .0831 & .0792 & .0808 & $\mathrm{H}$ \\
\hline Loadings & 6 & .0356 & .0455 & .0555 & .0573 & $\mathrm{H}$ & .0353 & .0453 & .0555 & .0572 & $\mathrm{H}$ \\
\hline Factor II & 3 & .0860 & .0866 & .0825 & .0836 & $\mathrm{H}$ & .0856 & .0860 & .0820 & .0827 & $\mathrm{H}$ \\
\hline \multirow[t]{2}{*}{ Loadings } & 6 & .0730 & .0776 & .0837 & .0850 & $\mathrm{H}$ & .0591 & .0648 & .0709 & .0729 & $\mathrm{H}$ \\
\hline & $\phi_{21}$ & .0661 & .0614 & .0579 & .0531 & $\mathrm{H}$ & .0651 & .0605 & .0579 & .0531 & $\mathrm{H}$ \\
\hline SS of & I & .2505 & .2417 & .2449 & .2365 & $\mathrm{H}$ & .1772 & .1750 & .1727 & .1686 & $\mathrm{H}$ \\
\hline Structures & II & .2440 & .2388 & .2405 & .2341 & $\mathrm{H}$ & .1629 & .1611 & .1567 & .1541 & $\mathrm{H}$ \\
\hline Anti-image & I & .1389 & .1339 & .1285 & .1229 & $\mathrm{H}$ & .1220 & .1195 & .1124 & .1094 & $\mathrm{H}$ \\
\hline contribution & II & .1578 & .1588 & .1506 & .1478 & $\mathrm{H}$ & .1405 & .1402 & .1328 & .1292 & $\mathrm{H}$ \\
\hline
\end{tabular}

Note: $\mathrm{N}=$ normal theory, $\mathrm{S}=$ simulation, $\mathrm{H} / \mathrm{F}=$ hit or fail.

Table 3

Standard errors for twelve-psychological-test data (direct oblimin, $\gamma=0$ )

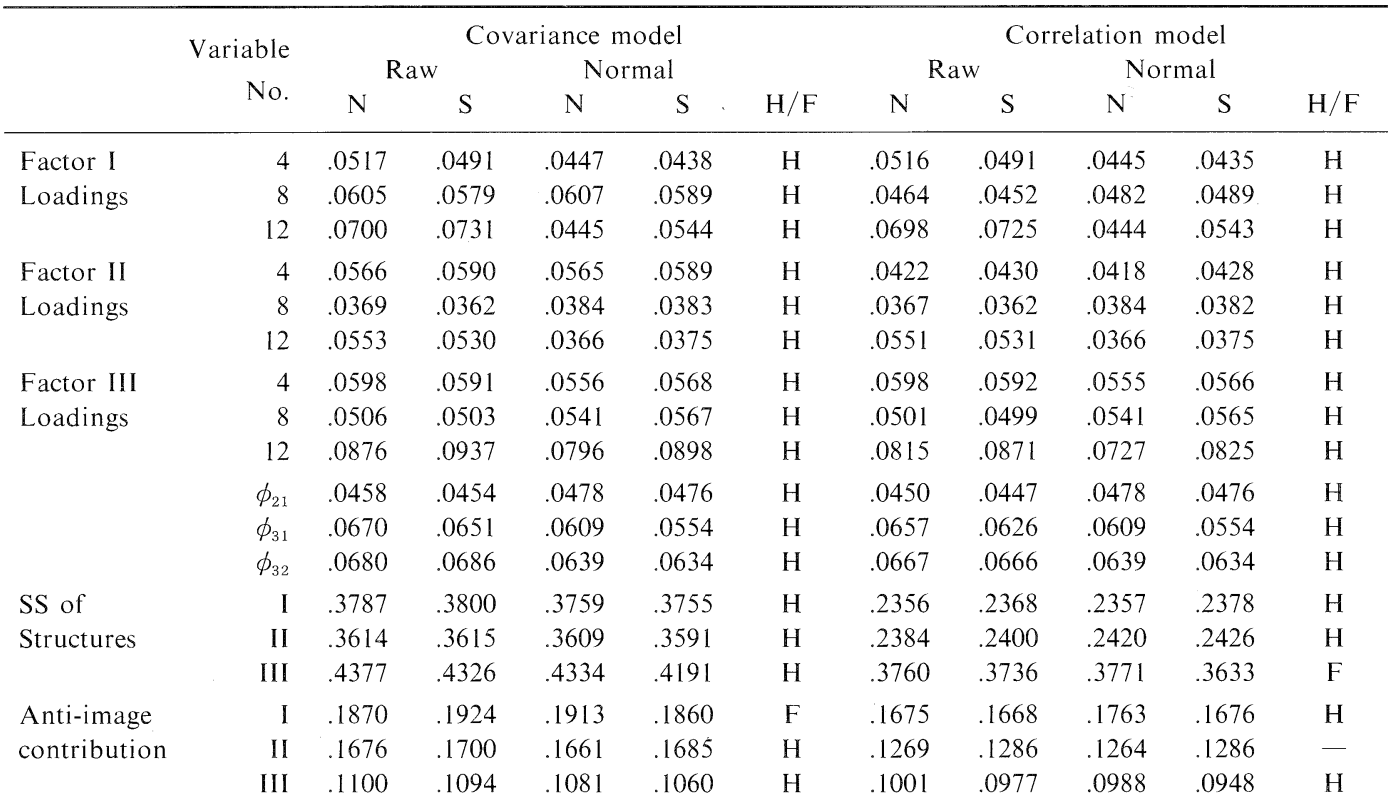

Note: $\mathrm{N}=$ normal theory, $\mathrm{S}=$ simulation, $\mathrm{H} / \mathrm{F}=$ hit or fail.

Table 1 からわかるように，規準化の有無によって因タＢでは 子パターンは大きくは変化していない.しかし, Table 2 の No. 6 の変量や Table 3 の因子I, II の No. 12 の変量の負荷は規準化の有無によって理論値 とシミュレーション值のいずれもかなり変化している ことがわかる。これらの結果は規準化オブリミン解の 標準誤差の理論的な推定値の適切性を示している.

次に規準化の有無が標準誤差に著しく影響する人工 的な例を相関行列モデルについて理論值により示す. Table 4 は二つのデータ（データB と C) の結果であ る.これらは斜交回転前の直交因子の負荷行列をデー $\Lambda^{\prime}=\left[\begin{array}{llllll}.80 & .80 & .10 & .40 & .30 & .01 \\ .40 & .30 & .01 & .80 & .80 & .10\end{array}\right]$ データCでは

$$
\Lambda^{\prime}=\left[\begin{array}{llllll}
.800 & .100 & .100 & .400 & .099 & .099 \\
.400 & .099 & .099 & .800 & .100 & .100
\end{array}\right]
$$

としたもので，標準誤差の算出には $N=300$ を仮定し た.

デー夕 B は小さな共通性の変量を含む例であるが， 規準化オブリミン解では小さな共通性の負荷の標準誤 差が素オブリミン解のものより相対的に小さくなって 
Table 4

Results for artificial data B and C (correlation model, $\gamma=0$ )

\begin{tabular}{|c|c|c|c|c|c|c|}
\hline \multirow{2}{*}{\multicolumn{2}{|c|}{$\begin{array}{c}\text { Variable } \\
\text { No. }\end{array}$}} & \multicolumn{2}{|c|}{$\begin{array}{l}\text { Raw oblimin } \\
\text { Loadings }\end{array}$} & \multicolumn{2}{|c|}{$\begin{array}{l}\text { Normal oblimin } \\
\text { Loadings }\end{array}$} & \multirow{2}{*}{$\begin{array}{l}\text { Comm- } \\
\text { unality }\end{array}$} \\
\hline & & $\mathrm{I}(\mathrm{SE})$ & II $(\mathrm{SE})$ & $\mathrm{I}(\mathrm{SE})$ & II (SE) & \\
\hline \multirow[t]{7}{*}{ Data B } & 1 & $.84(.30)$ & $.08(.26)$ & $.77(.28)$ & $.22(.39)$ & .80 \\
\hline & 2 & $.89(.19)$ & $-.05(.10)$ & $.80(.26)$ & $.11(.39)$ & .73 \\
\hline & 3 & $.13(.10)$ & $-.04(.10)$ & $.11(.07)$ & $-.02(.03)$ & .01 \\
\hline & 4 & $.08(.26)$ & $.84(.30)$ & $.22(.39)$ & $.77(.28)$ & .80 \\
\hline & 5 & $-.05(.10)$ & $.89(.19)$ & $.11(.39)$ & $.80(.26)$ & .73 \\
\hline & 6 & $-.04(.10)$ & $.13(.10)$ & $-.02(.03)$ & $.11(.07)$ & .01 \\
\hline & $\phi_{21}$ & \multicolumn{2}{|c|}{$.72(.06)$} & \multicolumn{2}{|c|}{$.46(.47)$} & \\
\hline SS of structures & & $2.35(.15)$ & $2.35(.15)$ & $2.06(.82)$ & $2.06(.82)$ & \\
\hline Anti-image cont. & & $.73(.14)$ & $.73(.14)$ & $1.02(.82)$ & $1.02(.82)$ & \\
\hline \multirow[t]{7}{*}{ Data C } & 1 & $.89(54)$. & $-.00(.19)$ & $.85(179)$. & $-.28(210)$. & .80 \\
\hline & 2 & $.08(40)$. & $.07(40)$. & $.14(.60)$ & $-.00(6.3)$ & .02 \\
\hline & 3 & $.08(40)$. & $.07(40)$. & $.14(.60)$ & $-.00(6.3)$ & .02 \\
\hline & 4 & $-.00(.19)$ & $.89(54)$. & $.85(179)$. & $.28(210)$. & .80 \\
\hline & 5 & $.07(40)$. & $.08(40)$. & $.14(.60)$ & $.00(6.3)$ & .02 \\
\hline & 6 & $.07(40)$. & $.08(40)$. & $.14(.60)$ & $.00(6.3)$ & .02 \\
\hline & $\phi_{21}$ & \multicolumn{2}{|c|}{$.80(1.70)$} & \multicolumn{2}{|c|}{$.00(589)}$. & \\
\hline SS of structures & & $1.38(26)$. & $1.38(26)$. & $1.52(1.61)$ & $.16(1.70)$ & \\
\hline Anti-image cont. & & $.30(26)$. & $.30(26)$. & $1.52(1.61)$ & $.16(1.70)$ & \\
\hline
\end{tabular}

Note: $\mathrm{SE}=$ standard error.

いるのがわかる. (Table 3 の No. 12 の変量の負荷も 規準化によって標準誤差が小さくなっているが，この 変量の共通性. 28 は 12 の変量の中で最小である。）ま た，規準化オブリミン解では因子間相関の標準詔差が 著しく大きくなっている.

データC $\mathrm{C}$ 単純でないパターンをもち，共通性の 小さい変量を含む場合であるが，きわめて大きな標準 誤差が得られている。また，デー夕Bで指摘した傾 向がここでも指摘できる，なお，規準化オブリミン解 では二つの因子は素オブリミン解のように対称にはな っていない。

データ B と C は特殊な人工例であるが，これらか ら共通性が小さい変量が多数含まれる場合に規準化を 行うと共通性の相対的に大であるものの推定值のばら つきが大となりやすいことが示唆されている。これは 実際の因子分析の適用に際しても留意すべきことであ ろう。すなわち，規準化をしない方法でも分析を行う ことや共通性が小さい変量が含まれている場合には, その変量を除いて結果を比較することなどが望ましい といえる。

\section{引用文献}

Archer, C. O., \& Jennrich, R. I. 1973 Standard errors for rotated factor loadings. Psychometrika, 38, 581592.
Clarkson, D. B., \& Jennrich, R. I. 1988 Quartic rotation criteria and algorithms. Psychometrika, 53, 251259.

Dixon, W. J. (Ed.) 1992 BMDP statistical software manual. Vol. 1. Los Angels: University of California Press.

Harman, H. H. 1976 Modern factor analysis. 3rd ed. Chicago: University of Chicago Press.

Jennrich, R. I. 1973 Standard errors for obliquely rotated factors. Psychometrika. 38, 593-604.

Jennrich, R. I. 1974 Simplified formulae for standard errors in maximum likelihood factor analysis. British Journal of Mathematical and Statistical Psychology, 27, 122-131.

Jennrich, R. I., \& Sampson, P. F. 1966 Rotation for simple loadings. Psychometrika, 31, 313-323.

小笠原春彦 1996 規準化オーソマックス法における 因子負荷の標準誤差 行動計量学, 23, 122-129.

Ogasawara, H. 1998a Standard errors for rotation matrices with an application to the promax solution. British Journal of Mathematical and Statistical Psychology, 51, 163-178.

Ogasawara, H. 1998b Standard errors of several indices for unrotated and rotated factors. Economic Review (Otaru University of Commerce), 49 (1), 21-69.

Ogasawara, H. 1999 Standard errors for procrustes solutions. Japanese Psychological Research, 41, 121130. 
SAS Institute Inc. $1990 S A S / S T A T$ user's guide. Vol. 1. Version 6, 4th ed. Cary, NC: Author.

Silvey, S. D. 1975 Statistical inference. New York: Chapman and Hall.

SPSS Inc. 1990 SPSS reference guide. Chicago: Author.

柳井晴夫・繁栘算男・前川畺一・市川雅教 1990 因 子分析一その理論と方法—朝倉書店

-1997.2.14 受稿, 1999.2.27 受理—

\section{付 録}

制約式のパラメータに関する偏微分

$$
\begin{aligned}
\frac{\partial g_{r s}}{\partial \beta_{i j}}= & \sum_{v \neq j} \frac{\beta_{i j} \beta_{i v} \beta_{i r}}{c_{i}^{2}} \phi^{s v}-\frac{\gamma}{p} \frac{\beta_{i j}}{c_{i}} \sum_{a=1}^{p} \sum_{v \neq j} \frac{\beta_{a v} \beta_{a r}}{c_{a}} \phi^{s v} \\
& +\frac{1}{2} \sum_{v \neq j}\left(\frac{\beta_{i v}^{2}}{c_{i}}-\frac{\gamma}{p} \sum_{m=1}^{p} \frac{\beta_{m v}^{2}}{c_{m}}\right) \frac{\beta_{i r}}{c_{i}} \phi^{s j} \\
& +\frac{\delta_{r j}}{2} \sum_{u=1}^{k} \sum_{v \neq u}\left(\frac{\beta_{i v}^{2}}{c_{i}}-\frac{\gamma}{p} \sum_{m=1}^{p} \frac{\beta_{m v}^{2}}{c_{m}}\right) \frac{\beta_{i u}}{c_{i}} \phi^{s u}
\end{aligned}
$$

$$
\begin{aligned}
& +\frac{1}{2} \sum_{u=1}^{k} \sum_{v \neq u}\left\{\sum_{a=1}^{p} \frac{\gamma}{p} \frac{\beta_{i v}^{2} \beta_{a u} \beta_{a r}}{c_{i}^{2} c_{a}} \phi^{s u}\right. \\
& \left.-\left(\frac{2 \beta_{i v}^{2}}{c_{i}}-\frac{\gamma}{p} \sum_{m=1}^{p} \frac{\beta_{m v}^{2}}{c_{m}}\right) \frac{\beta_{i u} \beta_{i r}}{c_{i}^{2}} \phi^{s u}\right\} \frac{\partial c_{i}}{\partial \beta_{i j}}
\end{aligned}
$$

ただし， $\frac{\partial c_{i}}{\partial \beta_{i j}}=2 \sum_{u=1}^{k} \beta_{i u} \phi_{u j}, \delta_{i j}$ はクロネッカーのデル タである。

$$
\begin{aligned}
& \frac{\partial g_{r s}}{\partial \phi_{e f}}= \frac{1}{2} \sum_{i=1}^{p} \sum_{j=1}^{k} \sum_{v \neq j}\left\{-\left(\frac{\beta_{i v}^{2}}{c_{i}}-\frac{\gamma}{p} \sum_{m=1}^{p} \frac{\beta_{m v}^{2}}{c_{m}}\right) \frac{\beta_{i j} \beta_{i r}}{c_{i}}\right. \\
& \cdot\left(\phi^{s e} \phi^{j f}+\phi^{s f} \phi^{j e}\right) \\
&+\left(-\frac{\beta_{i v}^{2}}{c_{i}^{2}} \frac{\partial c_{i}}{\partial \phi_{e f}}+\frac{\gamma}{p} \sum_{m=1}^{p} \frac{\beta_{m v}^{2}}{c_{m}^{2}} \frac{\partial c_{m}}{\partial \phi_{e f}}\right) \frac{\beta_{i j} \beta_{i r}}{c_{i}} \phi^{s j} \\
&\left.-\left(\frac{\beta_{i v}^{2}}{c_{i}}-\frac{\gamma}{p} \sum_{m=1}^{p} \frac{\beta_{m v}^{2}}{c_{m}}\right) \frac{\beta_{i j} \beta_{i r}}{c_{i}^{2}} \frac{\partial c_{i}}{\partial \phi_{e f}} \phi^{s j}\right\} \\
&(\boldsymbol{r} \neq s ; e>f)
\end{aligned}
$$

ただし， $\frac{\partial c_{i}}{\partial \phi_{e f}}=2 \beta_{i e} \beta_{i f}$ である。 